\title{
Erratum
}

\section{Facile Synthesis of the C1-C13 Fragment of Lyngbouilloside}

Julian Gebauer, Stellios Arseniyadis, * Janine Cossy* Synlett 2008, 712-714.

In the article published e-First, a structure was inadvertently missing from Scheme 2.

The correct scheme is shown below.

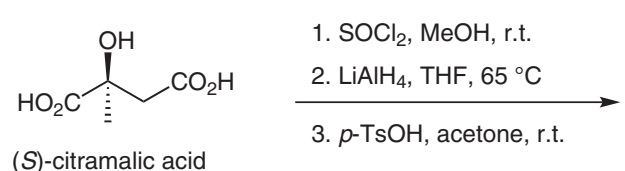

(S)-citramalic acid

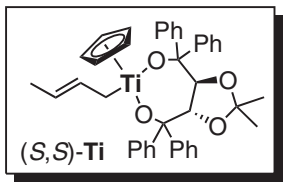<smiles>CC1(C)OC[C@@](C)(CCO)O1</smiles>

5
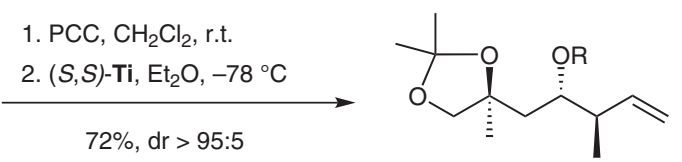

$\mathrm{NaH}, \mathrm{PMBBr}, \mathrm{DMF}$ $\mathrm{NaH}, \mathrm{PMBBr}$, DMF,
$\mathrm{THF}, 0{ }^{\circ} \mathrm{C}$ to r.t., $93 \%$<smiles>C=CC(=O)C[C@@H](O)CC1=CC(=O)OC(C)(C)O1</smiles>

Scheme 2 